\title{
AS IMAGENS DA TERRA NA POESIA DE CARLOS DE OLIVEIRA
}

Ida Maria Santos Ferreira Alves Universidade Federal Fluminense

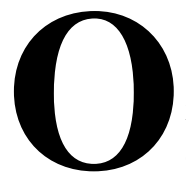

escritor português Carlos de Oliveira (1921-1981) raramente aceitou falar de si, contrário que era a qualquer dominância do biográfico sobre o literário. No entanto, as implicações de sua escrita no processo poético português contemporâneo não podem ser relegadas ao silêncio pela crítica universitária ${ }^{1}$, já que instituiu uma exemplar "teorização do poético", ação de rigor e de crítica estética ainda mais significativa se lembrarmos que houve um tempo em que o poeta pôs sua palavra à disposição da luta social, em prol de um projeto histórico que acreditava na transformação social de um país cerceado e dominado pela ditadura. Nesse contexto, a poesia era um instrumento de denúncia a serviço do projeto político libertário, o que seria a ação

${ }^{1}$ Em Portugal, verificando a produção recente a respeito da obra de Carlos de Oliveira, podemos afirmar que não há esse silêncio. Em 1996, foi defendida, na Faculdade de Letras da Universidade do Porto, tese de doutoramento, A Construção do Mundo na Poesia de Carlos de Oliveira, por Rosa Maria Martelo. Em 1995, publicaram-se Slow Motion Carlos de Oliveira e a pós-modernidade de Osvaldo M.Silvestre e Aventuras da Mimese na poesia de Carlos de Oliveira e na poesia de António Franco Alexandre por Américo António Lindeza Diogo, além de artigos, ensaios e comunicações diversas. No Brasil, embora o movimento de leitura da obra de Carlos de Oliveira esteja restrito a alguns centros acadêmicos de Letras, com a produção de poucas teses de doutorado, dissertações de mestrado e algumas comunicações, há que se salientar sua constância e significação. 
de uma "poética do testemunho", ${ }^{2}$ deslocando para a margem ou adiando a problematização da autonomia do objeto exteriores e, por isso, no decorrer de sua obra, buscou realizar o que desejava: "dar a têmpera do vento às palavras de ferro". 3

Quando, há alguns anos, elaboramos dissertações de Mestrado sobre a obra de Carlos de Oliveira, ${ }^{4}$ rastreamos as imagens responsáveis pela constituição de determinadas constelações simbólicas a que denominamos "paisagens poéticas". Reveladas, buscamos a sua significação, confrontando o projeto neo-realista (a poesia comprometida) com o projeto estético da modernidade: o poema como objeto criado e criador, lugar autônomo de transformação imagética e verbal. Para isso, utilizamos, então, como valioso subsídio a obra de Gilbert Durand, Les structures anthropologiques de l'imaginaire.

Como sabemos, nesse estudo já clássico, Durand valoriza ao máximo a função do imaginário e assume a perspectiva simbólica para estudar os arquétipos fundamentais da imaginação humana, a partir da convergência de idéias da Reflexologia, Tecnologia e Sociologia, estabelecendo dois grandes grupos de imagens simbólicas, a que ele denomina "regimes". Dessa forma, defende a tese de constituição de um "regime diurno com estruturas esquisomórficas (ou heróicas)" e de um "regime noturno com estruturas sintéticas (ou dramáticas) e místicas (ou antifrásicas)”. No desenvolvimento dessa tese, afirma o seu trajeto antropológico, participando da concepção geral do simbolismo imaginário de Gaston Bachelard e das teses de Piaget, o que significa o estabelecimento de um método de convergência e psicologismo

${ }^{2}$ Sigo reflexão do professor e crítico Manoel Gusmão, exposta em curso ministrado na Faculdade de Letras da Universidade Federal do Rio de Janeiro, em abril de 1998.

3 OLIVEIRA, 1992, P. 181.

${ }^{4}$ ALVES, 1990. 
metodológico. Apóia, nos estudos de Bachelard sobre uma fenomenologia da imaginação, dois pontos básicos: "l'imagination est dynamisme organisateur, et ce dynamisme organisateur est facteur d'homogénéite dans la représentation", 5 como esse autor demonstra em seu estudo não menos clássico sobre os quatro arquétipos fundamentais: água, terra, ar e fogo. Em Piaget, Durand concorda com a tese de que "les représentations subjectives s'expliquent 'par les accommodations antérieures du sujet' ao milieu objectif", 6 o que o leva a afirmar que "le symbole est toujours le produit des impératifs bio-psychiques par les intimations du milieu. C'est ce produit que nous avons nommé le trajet anthropologique, car la réversibilité des termes est le propre du produit comme du trajet."7

Sem nos prolongarmos na exposição das teses de Durand, que em tempo próprio foram muito divulgadas, destaquemos, como abordagem auxiliar para compreensão da obra poética de Carlos de Oliveira, uma leitura que dê conta das constelações simbólicas que demarcam áreas significativas em sua escrita. Entre elas, parece-nos bastante produtivo o tratamento simbólico dado ao elemento terra.

No imaginário humano, a terra é símbolo fundamental de vida, maternidade e intimidade, como se pode constatar através de inúmeros ritos agrários e narrações míticas. É o grande ventre maternal, responsável pela criação da vida e, como berço ou túmulo, é espaço de repouso para o homem. Por seu caráter maternal, assimila-se à figura feminina e, pelo desejo mítico de retorno à origem, propicia um imaginário de penetração e intimidade, em isomorfia com a água criadora. Além disso, pela resistência oferecida, por ser dos quatro elementos cósmicos aquele que

${ }^{5}$ DURAND, 1969, p.26.

${ }^{6}$ DURAND, 1969, p.38

${ }^{7}$ DURAND, 1969, p.39. 
oferece maior estabilidade, sustenta uma imaginação material, isto é, direciona o nosso olhar para a composição da matéria, com a percepção da dureza e da maciez, da interioridade e da exterioridade. Provoca, assim, o desejo de trabalhá-la para vencer a resistência.

$\mathrm{Na}$ poesia de Carlos de Oliveira, as imagens da terra são constantes e por isso detêm nossa atenção e provocam a leitura do valor simbólico desse elemento polivalente a reunir alguns temas arquetipais básicos no conjunto da obra do autor, seja em poesia, seja em prosa. Numa primeira sistematização, podemos determinar a existência de três níveis de imagens terrestres, acarretando cada um deles constelações simbólicas específicas: terra-pátria, terra-mãe e terra-poesia. Cada nível apresenta um conjunto imagético representativo dos esquemas de desolação, de penetração e de substância, respectivamente, inserindo-se ora num imaginário diurno ora no noturno sintético e místico, segundo proposto por Durand.

Lembremos que o Regime Diurno, representado no correr deste trabalho pelas iniciais $\mathrm{RD}$, define-se por ser um regime de antítese, a partir de um par simbólico fundamental: luz e trevas. Assim, nesse regime, compreendem-se as imagens simbólicas relacionadas às trevas (a luz é o contraste vitorioso) e as imagens responsáveis pela reconquista antitéticas das valorizações negativas. Fundamentalmente, esse regime reflete a angústia diante do tempo, com constelações imagéticas em torno da noite e do movimento de queda. As imagens da agressividade e devoração animal, da noite nefasta e da degradação moral simbolizam o terror humano perante a passagem do tempo e a presença da morte.

Para vencer o terror e fugir ao poder do tempo, hiperbolicamente representados, afirmam-se, por antítese, uma imaginação combativa e uma atitude heróica. Assim, à queda, às trevas e à animalidade / carnalidade se opõem o esquema ascensional, o arquétipo da luz uraniana e o esquema diairétique (separador), correspondente à 
dominante postural (verticalização, visão do alto e poder manual). No esquema ascensional, estão todas as imagens de elevação, luminosidade e espiritualidade. No esquema diairétique está a figura do herói purificado, empunhando suas armas cortantes capaz que é de vencer o mal e restabelecer o poder da luz.

O Regime Noturno (RN) está sob o signo da conversão e eufemismo, transformando o terror do tempo e da morte num valor afetivo positivo, ou seja, a noite anunciadora da aurora e a queda como lenta descida. Durand subdivide nesse regime dois grupos de símbolos: o primeiro "est constitué par une pure et simple inversion de le valeur affective attribueé aux visagens du temps", ${ }^{8}$ representa o RN com estruturas místicas ou antifrásicas, de dominante digestiva, valorizando a interioridade, a substância e a penetração; o segundo "va être axé sur la recherche et la découverte d'un facteur de constance au sein même de la fluidité temporelle", sintetizando os desejos de transcendência e as intuições próprias ao futuro, representando o RN com estruturas sintéticas ou dramáticas, de dominante copulativa, com a valorização do ritmo temporal, o simbolismo do eterno retorno e o progresso.

A terra-pátria é o nível imagético dominante na obra de Carlos de Oliveira dos anos 40 e 50, apresentando um código simbólico característico do ponto de vista neo-realista, representativo do clamor poético contra a situação sofredora e destrutiva em que se encontra seu país e seu povo. Assim, o poeta, assumidamente arauto do povo, "...trago notícias da fome /que corre nos campos tristes $/ \ldots / ",{ }^{10}$ transforma sua escrita em instrumento de luta contra o momento hostil que vivencia.

\footnotetext{
${ }^{8}$ DURAND, 1969, p.224.

9 DURAND, 1969, p.224.

${ }^{10}$ OLIVEIRA, 1992, p.45.
} 
Em alguns poemas desse primeiro momento, de Turismo (1942) a Descida aos infernos (1949), ${ }^{11}$ fundamentalmente, presentificamse esquemas de terror e desolação em relação à terra, acentuados ainda pelas águas sombrias, a noite voraz e animais noturnos como o morcego e o corvo. Esses esquemas são desenvolvidos a partir de imagens vegetais, animais e espaciais que refletem a podridão, a devoração, o medo, a destruição e o conflito entre as trevas e a luz, em nítida determinação de um imaginário de caráter diurno e suas estruturas antitéticas.

A estas imagens de uma terra-pátria negativa, agregam-se as imagens da terra-mãe, espaço mítico da origem. O poeta fala da terra, ora como o ventre original, de onde vêm todos os seres, ora como o cenário de destruição, na medida em que pode abrigar em seu interior a violência, o horror e a morte de seus filhos, sem nada fazer. A terra-mãe torna-se, para o poeta, a madrasta má, surda aos

${ }^{11}$ Os livros de poesia de Carlos de Oliveira citados no correr do estudo Turismo (T) - 1942, Mãe pobre (MP) - 1945, Colbeita perdida (CP) - 1948, Descida aos infernos (DI) - 1949, Terra de Harmonia (TH) - 1950, Cantata (C) - 1960, Micropaisagem (M) - 1968, Sobre o lado esquerdo (SLE) - 1968 e Pastoral (P) - 1977 estão reunidos em Obras de Carlos de Oliveira (1992). Devemos observar que o autor submeteu sua obra passada a intenso processo de reescrita, portanto, os textos reunidos em Obras de Carlos de Oliveiras apresentam muitas diferenças em relação aos textos originais, principalmente os primeiros títulos publicados. Não consideramos aqui essa questão, aceitando a Nota dos Editores que acompanha o volume que ora utilizamos: "Esta edição responde a um desejo de Carlos de Oliveira: reúne num único volume os textos que o Autor reconhecia (à data da sua morte) como constituindo a sua obra. [...] O texto que editamos segue o das últimas edições revistas pelo Autor." Lembremos que em nota final da última edição revista pelo autor, Carlos de Oliveira escreveu que "O autor remodelou, incluiu, cortou (sobretudo cortou) o que lhe pareceu necessário para alcançar um conjunto mais equilibrado. Os textos assim apurados constituem todo o "Trabalho Poético" de então que julga aproveitável. Qualquer outro poema que tenha publicado antes ou durante esse período fica portanto definitivamente excluído da sua obra." 
clamores desesperados dos homens, reduplicando as imagens negativas da terra-pátria.

Delineando o espaço original, a mãe natural, os fundamentos, as imagens terrestres em muitos poemas de Carlos de Oliveira representam o desejo de penetração, a posse da matéria, por meio da ação das raízes. Sob essa ótica, define-se um imaginário noturno de estruturas místicas com o desenvolvimento de esquemas simbólicos de descida, posse e interioridade.

Por outro lado, as raízes sustentam árvores que se elevam em direção ao céu, como afirmação vitoriosa da vida e superação de todo mal. Nesse sentido, na obra de Carlos de Oliveira, com o domínio fundamental da imagem arbórea que reúne em sua pluralidade, raízes (para o interior), tronco (movimento para cima, elevação ) e copa (expansão exterior), percebemos o sentido da própria poesia do autor, como se apresentará resumidamente. A árvore, como afirmação da verticalidade, fala de amadurecimento e progresso, do ritmo da vida, inserindo-se no imaginário noturno de estruturas sintéticas.

Os dois espaços anteriores, terra-pátria e terra-mãe, reúnemse na terra-poesia lavrada pelo poeta como lugar do trabalho transformador do real, pois aí ele experimenta a matéria verbal, luta com sua resistência, garantindo, por vezes, o poder ilusório do domínio da palavra.

Desenvolvendo esse terceiro espaço simbólico, encontram-se alguns dos arquétipos substantivos, segundo classificação de Durand, característicos do RN Místico como o microcosmo, a morada, o centro e a substância. Esses arquétipos refletem, na relação simbólica entre poeta e poesia, a necessidade de descer ao interior do poema, de encontrar o início do movimento poético, de encontrar na intimidade do poema a origem do Ser, o seu sentido. Empreende-se, assim, uma busca de conhecimento, afirma-se o desejo de encontrar as raízes do processo poético, reelaborando-se simbolicamente uma teorização em torno da constituição do objeto estético. 
Constituem-se, em decorrência, três conjuntos imagéticos que, por sua abrangência e importância, têm papel de destaque na compreensão da obra poética de Carlos de Oliveira.: a terra desolada, a terra penetrada e a terra substância.

Até 1950, sua poesia demonstra, de forma dominante, a preocupação do poeta com a realidade social de seu país. Sua escrita faz referência explícita à situação de opressão em que vive o povo português, metaforizada por uma paisagem de degradação, desolação e destruição. A partir de Terra de Harmonia (1950), o olhar do poeta vai examinar outras paisagens, deixando de lado o domínio da terra-pátria. No entanto, as imagens negativas, muito fortes nessa primeira fase, estarão ainda presentes na segunda, ainda que amenizadas.

Muitas são as imagens constitutivas do caráter sombrio e negativo da terra-desolada. Visando a uma maior clareza, essas imagens podem ser divididas em vegetais e animais, além de imagens em torno da noite, do fogo destruidor e da mineralização, como marca de secura e hostilidade.

O elemento vegetal se faz presente, na sua poesia, tanto como princípio de vida como certeza de morte. De vida, já que é promessa de renascimento e afirmação da germinação da terra. Nesse sentido, a floresta é a imagem ideal, pois é o lugar dessa esperança de nova vida. De morte, quando as imagens vegetais delimitam uma paisagem de dor, onde imperam o marasmo e a decomposição. $\mathrm{O}$ elemento vegetal, sob essa ótica, pode ser observado nos pântanos, à flor da terra, nas lagoas de águas negras, sob o sol em irreversível destruição, gerando, progressivamente, o mineral, o fóssil e o deserto, portanto, a vida petrificada.

Gândara, sem uma ruga de vento.

Sol e marasmo.

silêncio feito de troncos

e de pasmo. 
Campos, pinheiros e campos

quietos. Tanto,

o sol parado

encheu-me os olhos de espanto. ${ }^{12}$

Terra vista dos astros, breve e nua, na luz de azebre flutua

lembrando qualquer coisa violada

que à lenta luz boiasse, abandonada.

Como a madeira onde o caruncho brame, vermes ressoam pelo imenso fluido e um murmúrio apavorado flui do planeta, como se rangesse entre dentes de arame /.../

As florestas que daqui conheço, minerais, são as manchas da terra alucinadas, cardumes de mendigos ao poente nas estradas, nódoas só para os olhos astrais. ${ }^{13}$

A desolação da terra e o caráter destrutivo da existência possível nesse espaço são confirmados através das imagens teriomórficas. Essas imagens ligam-se não somente ao movimento, à agitação como também à agressividade e à crueldade do animal devorante. Símbolos do arquétipo do caos, certas imagens de animais são representativas do terror do tempo, simbolizando a destruição da matéria, a devoração do ser e a morte em oposição àquelas que simbolizam a luminosidade, a vida e a elevação vitoriosa. ${ }^{14}$

Na poesia de Carlos de Oliveira, são poucos os símbolos teriomórficos, mas os que aparecem confirmam, por sua vez, as trevas, a destruição, a devoração em confronto com a vida, a luz e

\footnotetext{
${ }^{12}$ OLIVEIRA, 1992, (T), p.28.

13 OLIVEIRA, 1992, (CP), p.99.

${ }^{14}$ Cf. DURAND, 1969, p.90.
} 
a construção. Em seu bestiário apresentam-se negativamente marcados: cavalos, cobras, touro, corvo, morcegos, aves negras, vermes, lobisomens, rãs e lobos. Com valor positivo está, de forma dominante, a ave solar, símbolo de toda elevação. Indicando o confronto entre o valor positivo da luz e a negatividade das trevas, aparece o galo, símbolo da aurora enfim vitoriosa.

A sombra tece do seu visco as flácidas
membranas que sustêm os morcegos;
e, enormes como bois, às rãs plácidas
serve-lhes de canga a escuridão dos pegos. ${ }^{15}$

As bruxas dançam de roda entre o visco dos morcegos, dançam de roda raspando as unhas podres de tojo na noite morta do povo como num tambor de rojo. ${ }^{16}$

E quando os galos quase mortos anunciarem por fim nos seus clarins desesperados o derradeiro tropel da tua ira, há de subir das chamas que moldaram o teu rosto de areia sobre dunas funestas um odor a trigo, a mel, a homens e à resina propícia das florestas. ${ }^{17}$

Símbolo ambivalente é a noite, porque ora aparece como duplo das trevas e da morte, inserindo-se, portanto, no RD, ora significa

\footnotetext{
15 OLIVEIRA, 1992, (CP), p.87.

${ }^{16}$ OLIVEIRA, 1992, (MP), p.51.

${ }^{17}$ OLIVEIRA, 1992, (DI), p.123.
} 
intimidade, agasalho e penetração típicos do RN Místico. Essa ambivalência, aliás, é muito clara. O poema $A$ noite inquieta ilustra a noite diurna, quando o poeta está só, em luta contra um mundo de tormenta, acreditando, porém, que é por meio de seu trabalho, por meio de suas mãos inquietas, que a noite poderá ser vencida.

Só em meu quarto, escrevo à luz do olvido;

deixai que escreva pela noite dentro:

sou um pouco de dia anoitecido

mas sou convosco a treva florescendo

/.../

Deixai que conte pela noite fora como a vigília é longa e desumana:

doira-me os versos já a luz da aurora, terra da nova pátria que nos chama. ${ }^{18}$

É exatamente pelo agrupamento das imagens da noite sombria, animais noturnos, vegetação hostil, água mortuária e fogo infernal que se desenvolve o tema arquetípico da dor e da destruição, dando-nos o poeta, na sua primeira fase, a visão dantesca da terra e a certeza do apocalipse. O arquétipo do caos é a concretização nefasta da terra-pátria devastada e da terra-mãe vingativa, descritas através de imagens próprias ao RD.

Três símbolos são fundamentais na poesia de Carlos de Oliveira para demonstrar o desejo de posse, penetração e intimidade em relação à terra, vista agora como terra-penetrada: floresta, árvore e raiz. São imagens complementares, já que a raiz sustenta a árvore e muitas árvores formam a floresta.

Desde tempos imemoriais, a floresta é o espaço da liberdade para o imaginário. No seu interior, realizavam-se cerimônias religiosas e com suas plantas preparavam-se poções mágicas. Lugar do oculto, do mistério e da magia, o espaço florestal representa a busca do saber e da origem.

${ }^{18}$ OLIVEIRA, 1992, (CP), p.83 
Carlos de Oliveira é também fascinado por essa imagem, como afirma em Oaprendiz de feiticeiro (1979a) e a sua poesia elabora com os elementos da floresta uma constelação simbólica que remete para o arquétipo da origem e da descida ao encontro do interior e do centro.

Cada passo, livro, acaso, opção, paixão, me levou sempre a uma floresta. Primeiro a Amazônia insondável onde nasci. Depois a infância, a literatura, a insonia, o amor, a constante derrota política, a antise da doença, a inadaptação aos códigos, a mania obsessiva do sonho. Floresta de florestas, desdobrando-se em mil raízes entrelaçadas, numa natureza demasiado pobre para tanto excesso. ${ }^{19}$

Em Turismo, a floresta lembra a infância na selva distante da Amazônia e, nos livros seguintes, está presente como metáfora do espaço onde se desenvolvem as estruturas do poema.
Selva
O negro, o índio
e o mais que me souber.
O fogo doutro céu,
o nome doutro dia.
tudo o que estiver
nos nervos
que me deu. ${ }^{20}$

\section{Em Terra de harmonia:}

Camponês, que plantaste estas árvores reais como pássaros vivos na verdura autêntica das ramagens, sabias bem que nada valem as asas fulvas e imaginárias nas florestas do tempo. Tu sim, que concebeste todas estas folhas, flores e frutos, toda esta terra de harmonia - no tamanho duma semente mais pequena que o coração das aves. ${ }^{21}$

\footnotetext{
19 OLIVEIRA, 1992, (AF), p.529.

${ }^{20}$ OLIVEIRA, 1992, (T), p.23.

${ }^{21}$ OLIVEIRA, 1992, (TH), p.132.
} 


\section{Em Cantata:}

As palavras
cintilam
na floresta do sono
e o seu rumor
de corças perseguidas
ágil e esquivo
como o vento
fala de amor
e solidão:
quem vos ferir
não fere em vão
palavras. ${ }^{22}$

Vê-se que a imagem da floresta é naturalmente decomposta para atingir a sua constituição, árvores e raízes, a partir de um ponto de vista cada vez mais próximo e interior. E, de um modo geral, a árvore é símbolo de grande importância no imaginário humano, representativo do mistério da vida e da renovação rítmica do Cosmos. Afirma Mircea Eliade:

...uma coisa parece evidente: que o Cosmos é um organismo vivo, que se renova periodicamente. O mistério da inesgotável aparição da vida é solidário do renovamento rítmico do Cosmos. É por essa razão que o Cosmos foi imaginado sob a forma de uma árvore gigante. O modo de ser do Cosmos e em primeiro lugar a sua capacidade de se regenerar sem fim é expressa simbolicamente pela vida da árvore. ${ }^{23}$

Como já se disse, a árvore é símbolo ambivalente. Por um lado, sua verticalidade representa a transcendência, o circuito entre o nível vegetal e o nível humano, acentuando as imagens de ressurreição e triunfo. Isso ocorre, porque, segundo Durand, em muitos mitos, a árvore, por sua verticalidade, é símbolo do microcosmo vertical que é o homem. ${ }^{24}$ Por outro lado, na direção oposta, as raízes

\footnotetext{
${ }^{22}$ OLIVEIRA, 1992, (C ), p.177.

${ }^{23}$ ELIADE, s.d., p.157.

${ }^{24}$ DURAND, 1969 , p.395.
} 
penetram na terra e lá se expandem, como árvore invertida, em busca da intimidade com a matéria terrena. Penetrando na terra, vivendo na ausência da luz, a raiz une a vida à morte, o interior ao exterior, o oculto ao revelado, sendo, portanto, um símbolo unificador, atingindo, como afirma Durand, "la totalité du cosmos dans as genése et son devenir". 25

A raiz é, assim, imagem dinâmica, ponto de encontro de forças diversas, elemento simbólico da permanente busca, da inquietação humana. Junto à imagem da árvore, forma um complexo simbólico relacionado ao desejo de totalidade, criação e origem. Por isso, compreende-se que Bachelard afirme: "L'imagination est un arbre."26

Na poesia de Carlos de Oliveira, floresta - árvore - raízes falam de metamorfoses, da lenta, porém constante e progressiva, criação, da intimidade material relacionada à poesia. No seu movimento para baixo, para o interior, as raízes revelam a ânsia de conhecimento e de domínio da matéria verbal; no seu movimento para o alto, a árvore afirma o caráter transcendental da palavra poética, superação da materialidade.

As raízes da árvore
rebentam
nesta página
inesperadamente
por um motivo
obscuro
ou sem nenhum motivo.
invadem o poema
e estalam
monstruosas
buscando qualquer coisa
que está
em estratos
fundos
/.../

${ }^{25}$ DURAN, 1969, p.395.

${ }^{26}$ Cf. BACHELARD, 1974, p.300.

${ }^{27}$ OLIVEIRA, 1992, (M), p.259. 
A árvore poética é, assim, a representação simbólica da ação transformadora da palavra poética e a própria imagem ambivalente do trabalho com a poesia. Forma vertical, a imagem arbórea é associada, na poesia de Carlos de Oliveira, à coluna, torre, salto e vôo, na comprovação de que o poema é forma em progresso, sempre à procura do sentido além.

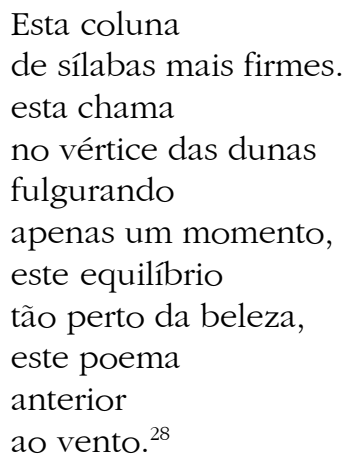

À medida que os símbolos terrestres presentes em sua poesia clarificam o desejo de descer, penetrar e possuir, falando de origem, do centro, do interior da substância poética, constata-se o domínio de um imaginário noturno místico. Por outro lado, já que, em sua escrita, a palavra poética é imagem isomorfa da árvore, da ave, da chama e da espiral pelo desejo de verticalidade, há também os esquemas de amadurecimento e progresso, no trânsito constante entre o passado e o futuro, entre as imagens guardadas e relembradas pelo poeta e o futuro do poema, forma sempre desejando outra forma, na ótica do RN Sintético.

Em Terra de Harmonia (1950), afirma-se uma tendência que nos poemas anteriores era escamoteada pelo discurso social e combativo: a pesquisa da matéria poética. A poesia é terra lavrada, lugar de intimidade onde estão poeta e palavra, numa relação lenta, interior e microcósmica.

${ }^{28}$ OLIVEIRA, 1992, (SLE), p.204. 
O levantamento de imagens constata que na poesia de Carlos de Oliveira, a partir dessa obra, há o pleno domínio do RN Místico com o esquema verbal confundir, o que significa dizer que há uma série de imagens determinantes dos esquemas descer, penetrare possuir. Notese, porém, que o domínio do RN Místico não exclui a presença do RN Sintético, como já se apontou.

Se, como terra penetrada, os símbolos vegetais revelam a preocupação com o poético, têm-se, agora, outros símbolos indiciadores de ser a escrita um ato de intimidade, a transformação prazerosa da "substância" verbal. O poeta é o dominador da matéria e a poesia é como terra revolvida pelo trabalho de mãos inquietas. Bachelard, em prefácio a La terre et les rêveries de la volonté, afirma: "Nous montrerons que le langage poétique quand il traduit les images matérielles est une véritable incantation de energie" ${ }^{29}$

Assim, Carlos de Oliveira trabalha uma simbologia referente à materialidade do discurso poético. Se, na primeira fase, observa-se o domínio de imagens da dor e da luta, agora, numa segunda fase, predominam as imagens terrestres em direção ao interior, ao oculto, ao trabalho, à construção e à transformação dessa materialidade. Seguindo essa direção, o discurso poético sofre uma progressiva mineralização, ou seja, o poeta trata as palavras como minerais a lapidar, ressaltando o caráter mineral da folha de papel e das palavras grafadas nessa folha. Escrever, portanto, é percorrer um deserto e encontrar nele formas significativas.

Nessa fase, as imagens poéticas se organizam a partir de um olhar que vê em tudo sua constituição mineral, sendo recorrente o uso de um vocabulário nessa área semântica como mica, rocha, xisto, sílica, zinco, aço, pedra, petrificado, cal, estalactites, metais, minas, ferro, cálcio, lava, diamante, argila, quartzo, feldspato, vidro, cristal, prata, tijolo, ácido, árido, granito e rochoso. Esse olhar material busca apreender o interior das coisas e de paisagens como a gruta, as dunas, a colina oca, a floresta, a folha de papel, o quarto e o próprio poema.

${ }^{29}$ BACHELARD, 1976b, p.8. 
A pesquisa material é necessária para a realização do trabalho de metamorfose, seja ele da natureza, seja do humano. Dessa forma, observar os elementos constitutivos de algo é compreender a relação entre esses fragmentos e a unidade. Assim, na floresta está a árvore e nesta as raízes; na terra está o estrume, produto da ação transformadora de substâncias, o qual, por sua vez, auxiliará na transformação de algo; nas grutas, estão as estalactites, nelas a ação da água na pedra; nas dunas, os grãos de areia; no papel, a marca da madeira, da árvore e das palavras.

Enfim, numa relação en abîme, uma substância revela outra e a ação do poeta capta esse dinamismo, tornando seu trabalho poético um exercício de aprofundamento para encontrar os fundamentos do processo de criação. Conseqüentemente, os poemas não são mais isolados, fechados em seu sentido, mas unidades dialogantes, complementados por outros poemas, numa reprodução formal da busca cada vez mais minuciosa, mais interior e inquiridora. Os poemas de Micropaisagem representam bem essa afirmação.

As raízes da árvore

rebentam

nesta página

inesperadamente

por um motivo

obscuro

ou sem nenhum motivo,

invadem o poema

e estalam

monstruosas

buscando qualquer coisa

que está

em estratos

fundos, 
II

talvez poços,

secretas

fontes primitivas,

depósitos, recessos

onde haja

um pouco de água

que as raízes

procuram

de página

em página

com a sua obsessão,

múltiplos filamentos

trespassando

o papel,

III

seguindo o fio

da tinta

que desenha

as palavras

como podem

crescer

de tal modo

IV

no poema,

se a árvore

foi dispersa

em pranchas de soalho,

em móveis e baús ${ }^{30}$

${ }^{30}$ OLIVEIRA, 1992, p.235-238 
Essa volta para o interior, esse contato mais íntimo com a matéria poética gera um certo hermetismo semântico difícil para o leitor acomodado, já que a linguagem poética é seu próprio referente. Será preciso, portanto, que o leitor realize também seus ritos de descida e penetração para tomar posse igualmente da terrapoesia, ou seja, realize uma aprendizagem sobre a prática de representação estética. Esse caminho compara-se, assim, a uma proposta alquímica, como se a poesia fosse uma alquimia de palavras, em busca da transubstanciação do verbo, pois... "l'alchimiste, comme le poète, n'a qu'un désir: celui de penétrer amoureusement les intimités.".31

Contar os grãos de areia destas dunas é o meu ofício actual.

Nunca julguei que fossem tão parecidos, na pequenez imponderável, na cintilação de sal e oiro que desgasta os olhos ${ }^{32}$

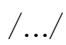

Localizar

na frágil espessura

do tempo

que a linguagem

pôs em vibração,

o ponto morto

onde a velocidade

se fractura

e aí

determinar

com exatidão

o foco

o silêncio... ${ }^{33}$

31 DURAND, 1969, p.294.

32 OLIVEIRA, 1992, (SLE), p.222.

33 OLIVEIRA, 1992, (M), p.238. 
Se uma película de vidro adere à pele da pedra; se algum vento vier.

Afere-lhe o esplendor; martela, fere: um som de ferro no exterior; por dentro outra textura mais espessa. Poisa como um verniz depois o ar suave a sua laca no esmalte fracturado. E levanta-se então. Minuciosamente. Ergueu-se o halo das colinas, a lenta beleza levitada em cada grão de pedra. /.../

Rodar a chave do poema e fecharmo-nos no seu fulgor por sobre o vale glaciar. Reler o frio recordado. ${ }^{30}$

Vê-se, portanto, que o desejo de penetrar na matéria verbal, de ocupar um microcosmo poético ao encontro de sentidos fundamentais, concretiza-se a partir de uma constelação de imagens submetida aos esquemas verbais descer, possuir e penetrar, típicos do RN Místico.

Pela análise do levantamento simbólico realizado, verifica-se concretamente a afirmação bastante repetida de haver duas fases na obra poética de Carlos de Oliveira. Na primeira, predomina o Regime Diurno, com o domínio de um discurso imagético antitético e a permanente oscilação entre a poesia em função do povo e a poesia em direção à sua própria elaboração. Assim, o poeta assume caráter

${ }^{34}$ OLIVEIRA, 1992, (P), p. 391-392. 
guerreiro e põe sua poesia a serviço da causa social. Deseja, através do domínio verbal, separar o bem do mal, vencendo as trevas políticas que envolvem sua terra e, particularmente, superar o temor e a angústia que o tempo irrevogável provoca em todo ser. Podese afirmar, portanto, que esse predomínio ratifica, de início, a fidelidade de Carlos de Oliveira às propostas do Neo-Realismo português pelo desenvolvimento de um discurso poético de luta e de denúncia, com forte consciência histórica e coletiva, além de ideais de superação e vitória.

Nessa direção, o RD possui esquemas simbólicos que representam bem o caráter antitético da escrita neo-realista, na medida em que é constante o confronto entre dominador e dominado, pobreza e riqueza, saber e ignorância, opressão e liberdade. Reforçando esteticamente essa dualidade, sua escrita fala de metáforas neo-realistas permanentes como noite vs aurora, luz vs trevas, além de silêncio vs denúncia. No entanto, o poeta não pára aí e o que se acompanha é a minuciosa e exemplar reflexão sobre o discurso poético e sua constituição.

Assim, ao RD vêm somar-se as estruturas sintéticas e místicas do Regime Noturno. Não há separação nítida, ou a exclusão de um regime para domínio absoluto de outro. O sentido das constelações simbólicas mostra que, a partir de Cantata (1960), realmente predominam imagens noturnas, à proporção que a poesia de Carlos de Oliveira desenvolve um maior e mais conseqüente questionamento sobre a matéria poética e seu trabalho, principalmente através de imagens típicas do RN Místico.

Nesse momento, afirma-se o poeta-construtor. Seu poema é elaboração de sentidos, é o cálculo do vôo, é a arquitetura de formas, é a experiência de significados. A revolução, portanto, não se relaciona somente ao combate por mudanças sociais, mas também à valorização da poesia, à revitalização de estruturas verbais esgotadas, ao diálogo intertextual, para enriquecimento comum e afirmação da ação transgressora da palavra poética.

Pela constante relação dos dois regimes, Carlos de Oliveira demonstra que o discurso poético não abdica da função social, 
porém, além disso, é uma pesquisa de formas e sentidos, uma arquitetura verbal que examina sua necessária autonomia.

Através da análise das estruturas simbólicas do seu discurso poético, destacando-se aqui as imagens da terra, podemos comprovar que ao poeta-arauto, engajado politicamente, corresponde um imaginário de luta, purificação e desejo de transcendência, refletindo-se, formalmente, na manutenção do verso tradicional, na discursividade e no domínio da emotividade. Ao poeta-artesão, engajado poeticamente, corresponde um imaginário de intimidade com a matéria poética, com o desenvolvimento formal mais preocupado em atingir a concisão, a objetividade e o rigor.

A modernidade de sua obra está, portanto, na ultrapassagem de propostas e discurso neo-realistas para constituir uma escrita poética questionadora do real e do trabalho estético, num exercício da poesia que exige do autor a experimentação e do leitor uma outra sensibilidade textual. Isso significa dizer também que o poeta não se submete a uma retórica poética esgotada e continua, com rigor e fidelidade, a procurar desvelar na escrita outras formas de representar o mundo ou criá-lo. Para muitos, Carlos de Oliveira tornou-se hermético e perdeu a utopia da História; para os que aceitaram o jogo com a palavra, compartilharam a lavratura dessa terra-poesia, o escritor expôs com clareza a crise da representação que a modernidade (ou pós-modernidade) vivencia e demonstrou que a utopia deslocou-se do projeto histórico para a prática estética, ao encontro do homem e da liberdade da criação. 


\section{Referências Bibliográficas}

ALVES, Ida M. S. Ferreira. As paisagens poéticas de Carlos de Oliveira. Niterói: UFF, 1990. Dissertação de Mestrado.

BACHELARD, Gaston. La terre et les réveries de la volonté; essai sur l'imagination des forces. Paris: José Corti, 1976.

BACHELARD, Gaston. La terre et les réveries du repos; essai sur les images de l'intimité. Paris: José Corti, 1974.

DIOGO, Américo António Lindeza. Aventuras da mimese na poesia de Carlos de Oliveira e na poesia de António Franco Alexandre. Pontevedra/Braga: Cadernos do povo, 1995.

DURAND, Gilbert. Les structures anthropologiques de l'imaginaire. Paris: Bordas, 1969.

ELIADE, Mircea. O mito do eterno retorno. Lisboa: Edições 70, [s.d.]

OLIVEIRA, Carlos de. Obras de Carlos de Oliveira. Lisboa: Caminho, 1992.

PEREIRA, Rosa Maria Martelo Fernandes. A construção do mundo na poesia de Carlos de Oliveira. Porto: Faculdade de Letras da Universidade do Porto, 1996. Dissertação para doutoramento em Letras.

SILVESTRE, Osvaldo M. Slow motion Carlos de Oliveira e a pósmodernidade. Braga/Coimbra: Angelus Novus, 1995. 


\section{Resumo}

Este trabalho analisa a obra poética de Carlos de Oliveira a partir de um ponto de vista metodológico que deseja descrever as configurações simbólicas em torno do elemento terra, aplicando especialmente as teses desenvolvidas por Gilbert Durand em seu Les Structures Anthropologiques de l'Imaginaire. Temos o propósito de demonstrar que o projeto poético do autor progride de uma escrita de intervenção social, cânone neo-realista, para uma escrita de teorização do próprio poético que discute a representação.

\section{Abstract}

This paper analyses the poetic works of Carlos de Oliveira from a methodological point of view that wishes to describe the simbolical configurations around the element earth aplying specially theses developed by Gilbert Durand in his Les Structures Anthropologiques de l'Imaginaire. We have the purpose of demostrating that his poetical works evolves from a social writing, "neo-realista" canon, to a writing of theorization about the poetics itself what discuss the representation. 